\title{
Fairness of performance evaluation procedures and job satisfaction: the role of outcome-based and non-outcome-based effects
}

\author{
Chong M. Lau, Kuan M. Wong and Ian R.C. Eggleton*
}

\begin{abstract}
Prior management accounting studies on fairness perceptions have overlooked two important issues. First, no prior management accounting studies have investigated how procedural fairness, by itself, affects managers' job satisfaction. Second, management accounting researchers have not demonstrated how conflicting theories on procedural fairness can be integrated and explained in a coherent manner. Our model proposes that fairness of procedures for performance evaluation affects job satisfaction through two distinct processes. The first is outcome-based through fairness of outcomes (distributive fairness). The second is non-outcome-based through trust in superior and organisational commitment. Based on a sample of 110 managers, the results indicate that while procedural fairness perceptions affect job satisfaction through both processes, the non-outcome-based process is much stronger than the outcome-based process. These results may be used to develop a unified theory on procedural fairness effects.
\end{abstract}

Keywords: fairness; performance evaluation procedures; trust; commitment; satisfaction

\section{Introduction}

Considering the importance and pervasiveness of performance evaluation procedures (processes) in organisational control systems, it is likely that the fairness of such procedures will have important behavioural implications for organisational members. This study therefore investigates if and how the fairness of procedures employed by organisations to evaluate their employees' performance and determine compensation affects employee job satisfaction.

Figure 1 presents the conceptual model underlying our study. It proposes that the effect of fairness of performance evaluation procedures (procedural fairness) on job satisfaction is indirect through two distinct processes. The first process is outcomebased through fairness of outcomes (distributive fairness) (path 1-2-5). The second process is nonoutcome-based through trust in the superior (path 1-3-5) and organisational commitment (path 1-4-5).

${ }^{*}$ Chong M. Lau is Associate Professor at UWA Business School, The University of Western Australia, Kuan M. Wong is a Research Scholar at the School of Accounting. Finance and Economics, Edith Cowan University and Ian R.C. Eggleton is Professor of Accounting at the School of Management, The University of Waikato. Correspondence should be addressed to Associate Professor Chong M. Lau, UWA Business School, Accounting and Finance (M250), The University of Western Australia, 35 Stirling Highway, Crawley, Western Australia, 6009. Tel: 6186488 2910. Fax: 6186488 1047.E-mail: chong.man.lau @ uwa.edu.au

This paper was accepted for publication in January 2008.
Procedures for performance evaluation are selected for investigation because the design of management accounting controls, including appropriate performance evaluation and compensation arrangements, is a crucial management function to promote positive employee attitudes and behaviours (Horngren el al., 2006; Merchant and van der Stede, 2007). Performance evaluation is also an important management accounting research area (Brownell and Dunk, 1991; Lau et al., 1995; Hartmann, 2000). Not surprisingly therefore, the systematic evaluation of fairness perception in the management accounting context was first undertaken by Hopwood (1972) in his study of performance evaluation methods. He and Otley (1978) both studied the effects of performance evaluative style on fairness perceptions. Subsequent studies (e.g. Lindquist, 1995; Magner and Johnson, 1995; Lau and Lim, 2002; Staley and Magner, 2006) have also investigated fairness-related issues in the management accounting context.

Several important conclusions could be drawn from prior studies. First, early studies on procedural fairness in a legal setting have found procedural fairness to be related to distributive fairness (e.g. Thibaut and Walker, 1975, 1978). Distributive fairness or fairness of outcomes may be defined as the judgments on how fair are the decisions that are made (Folger and Konovsky, 1989: 115; Greenberg and Folger, 1983: 236). A study by McFarlin and Sweeney (1992) found that distributive fairness, in turn, influences job satisfaction. 


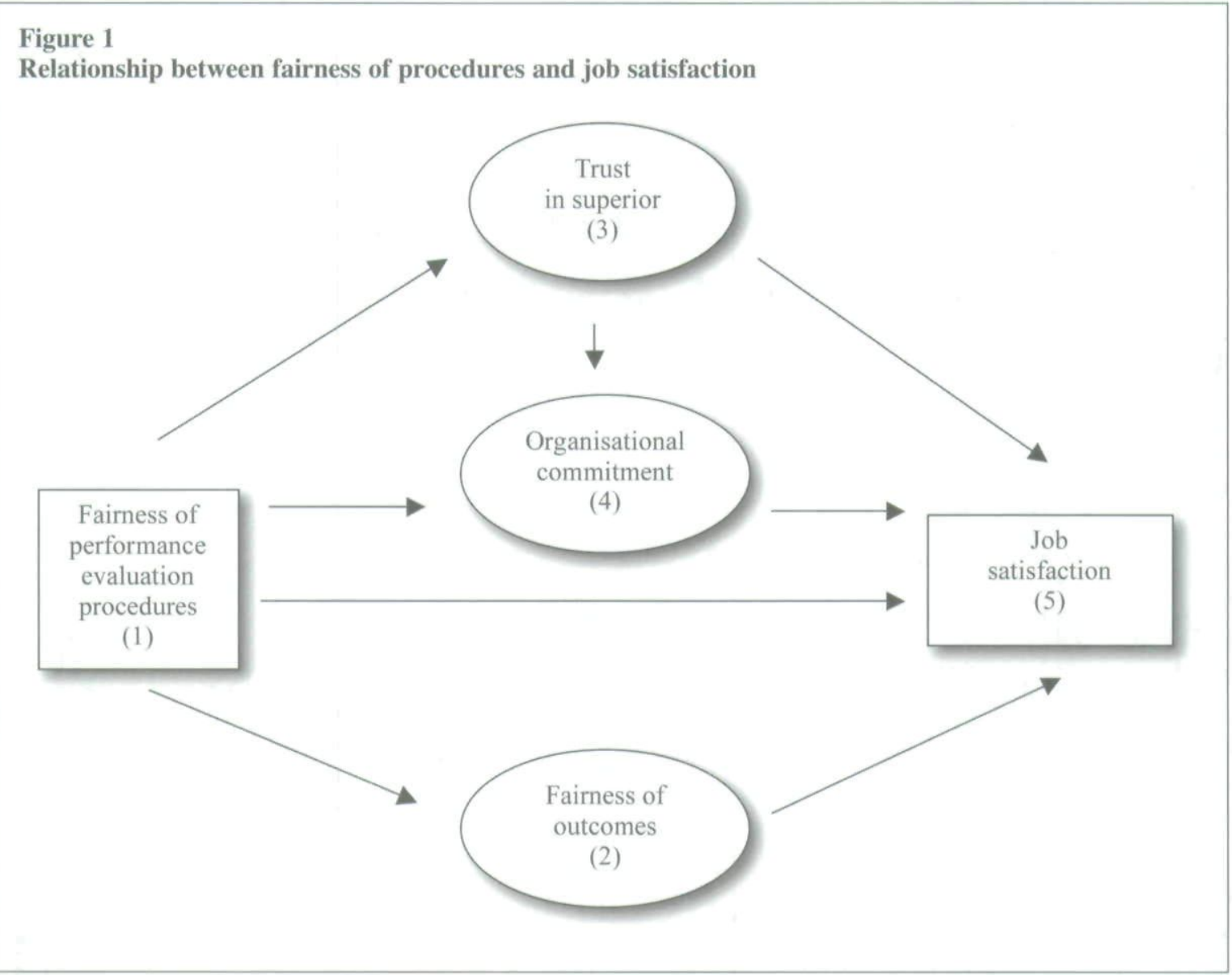

These findings suggest that the effects of procedural fairness on employee job satisfaction may be indirect through distributive fairness. Yet, to date, these likely indirect relationships of procedural fairness on job satisfaction through distributive fairness (path 1-2-5 in Figure 1) have not been systematically investigated.

The indirect effects of procedural fairness on job satisfaction through non-outcome-based or emotional processes are also yet to be investigated. Prior studies have found that procedural fairness has important emotional effects. Specifically, several studies have found a significant relationship between procedural fairness and employee trust in management or supervisor (e.g. Konovsky and Pugh, 1994; Magner and Johnson, 1995; Staley and Magner, 2006). A link was also found between procedural fairness and organisational commitment (Folger and Konovosky, 1989). Since these psychological effects (trust and organisational commitment) may be related to employee job satisfaction, it is likely that the relationship between procedural fairness and employee job satisfaction is indirect via (1) trust and (2) organisational commitment (see path 1-3-5 and path 1-4-5 in Figure 1).

The above discussion suggests that procedural fairness may be related to several outcome and non-outcome variables. Our study attempts to con- tribute to the literature by the development of a model which integrates the two important processes by which fairness of employee evaluation procedures affects employee behaviours. The development of such a model is beneficial. First, it may minimise the confusion arising from the interpretation of several bivariate relationships, each studied in isolation. Instead, an integrated model may help us to understand how and where the various bivariate relationships found in prior studies fit and are linked together. Second, it may clarify whether the total effects between procedural fairness on job satisfaction are direct (as suggested by bivariate analysis) or indirect. More importantly, to date, no study has investigated systematically, with an integrated model, the two likely processes. An integrated model will facilitate the two distinct processes to be studied simultaneously allowing us to distinguish between (1) the outcome-based effects through distributive fairness, and (2) the non-outcome-based effects through trust and commitment.

Our study also differs from prior studies in terms of the variables incorporated in the models. Specifically, our model investigates the important psychological effects of procedural fairness through organisational commitment on job satisfaction. While commitment was studied by 
Wentzel (2002), her interest was in goal commitment and not organisational commitment. Similarly, while satisfaction was studied by Lindquist (1995), his interest was in task satisfaction rather than overall job satisfaction. Hence, the complex relationships among procedural fairness, organisational commitment and overall job satisfaction in general and, more importantly, the process by which procedural fairness affects job satisfaction through organisational commitment, are yet to be systematically evaluated in a coherent manner. In the next section, relevant studies are examined to develop a theoretical basis for the hypotheses to be tested. Subsequent sections respectively describe the method, results and the implications for theory and practice.

\section{Hypotheses development}

\subsection{Concept of procedural fairness (justice)}

Lind and Tyler (1988: 3,216) conceptualise procedural fairness as the judgments on how fair are those social norms which deal with 'how decisions are made' and 'how people are treated by authorities and other parties'. This concept is broader than earlier concepts which essentially suggest that the determinant of high procedural fairness is process control (participation) by those affected by the decisions and the consequence is the achievement of equitable outcomes (Thibaut and Walker, 1975). Lind and Tyler's broader concept includes other determinants and other consequences of procedural fairness. These other determinants include consistency, bias suppression, accuracy of information, correctability and ethicality (Leventhal, 1980). Other consequences include those emotional effects which are over and above the achievement of fair outcomes. Because this broad concept encompasses both outcome-based and non-outcomebased effects, two distinct theories are needed to explain its effects. Hence, the self-interest model (Lind and Tyler, 1988: 222) can explain those effects which are outcome-based and attributable to the use of fair procedures strictly for the purpose of achieving fair outcomes. In contrast, the group value model (Lind and Tyler, 1988) is used to explain those emotional effects which are over and above those attributable to the achievement of fair outcomes. These effects include those positive attitudes an individual harbours towards the group (organisation) and the leaders of the group arising from group procedures which enhance the individual's 'dignity as a full-status member of the group'(Lind and Tyler, 1988: 237).

\subsection{Fairness of performance evaluation procedures and job satisfaction (path 1-5)}

In this study, job satisfaction is selected as the dependent variable. The study of job satisfaction is important. Lind and Tyler (1988: 176-177) found that satisfaction is one of the principal consequences of procedural fairness. They concluded that 'the great practical value of procedural justice lies in ... its value as a source of ... satisfaction'. Hartmann (2000) has also considered job satisfaction a more appropriate dependent variable than managerial performance in studies on performance evaluation. According to him, prior studies on performance evaluation systems have consistently relied on role theory to explain the relationships between evaluation systems and employee behavioural outcomes. Role theory involves role conflict and role ambiguity and these variables "typically point to such interpersonal and work-related factors as ... job satisfaction' (Hartmann, 2000: 467) and not on job performance.

The study of job satisfaction is also important in its own right. Locke (1976: 1297) defines job satisfaction as 'a pleasurable or positive emotional state resulting from the appraisal of one's job or job experiences'. Harrison (1992: 8) regards job satisfaction 'as leading to organisationally important outcomes including absenteeism and turnover, motivation, job involvement and performance'. Employees' satisfaction or dissatisfaction with their jobs can have multiple and serious consequences. Dissatisfied employees are more likely to engage in such actions as job avoidance and withdrawal, aggressions, defiance, protest, and psychological defensiveness. Additionally, employees' happiness is an important aspect of employee wellbeing. It is therefore not surprising that job satisfaction is a major behavioural outcome in management accounting research (e.g. Chenhall and Brownell, 1988; Frucot and Shearon, 1991; Harrison, 1992).

Fairness perceptions, including those arising from the use of different methods to evaluate employee performance, are an important research area. Both Hopwood (1972) and Otley (1978) hypothesise that performance evaluative methods affect employees' perceptions of fairness. For instance, Hopwood (1972: 174) considers performance evaluations based on an inflexible use of accounting data as a 'biased indicator of managerial performance ... (and) potentially inequitable' His results indicate that the performance evaluation methods affect justness of evaluation which, in turn, affects employee satisfaction.

Several management accounting studies have linked performance evaluation procedures to job satisfaction (e.g. Brownell, 1982; Harrison, 1992; Lau and Sholihin, 2005). The justification is based on the premise that performance evaluation and the compensation employees receive are a reflection of the extent of employees' success or failure in performing their tasks. Feelings of success and failure are important determinants of job satisfaction (Locke and Latham, 1990: 237-238). 
Based on the above discussion, it is reasonable to conclude that fairness of performance procedures may affect job satisfaction. However, these effects are likely to be indirect through two distinct processes including (1) fairness of outcomes (distributive fairness), and (2) trust in the superior and organisational commitment. The following sections provide the theoretical justification for these propositions.

\subsection{Intervening effect of fairness of outcomes (path 1-2 and path 2-5)}

Lind and Tyler (1988) conceptualise fairness of outcomes (distributive fairness) as the judgments on how fair are those norms which deal with the outcomes people receive. Tang and SarsfieldBaldwin (1996: 25) suggest that 'distributive justice deals with the ends achieved (what the decisions are)'. Concepts of distributive fairness are based on the principle of equity when the outcome an individual receives is proportional to the individual's contribution. Adams (1965) suggests that because equity is such a fundamental norm, individuals will experience inequity distress when the allocation of outcomes among group members is not proportional to contribution. Perception of distributive fairness is therefore aroused not by absolute outcomes, but by a comparison of the proportion allocated to an individual relative to the proportion allocated to other group members. The theory of relative deprivation (Merton and Rossi, 1957) similarly suggests that individuals judge their situation not in absolute terms, but by comparing them to the situation of others. Individuals who receive favourable outcomes in objective terms may still be discontented if they perceive others are better rewarded. Hence, concepts of fairness of outcomes are relative concepts. The relative concept of fairness of outcomes is therefore used in our study.

Fairness of performance evaluation procedures may be associated with fairness of outcomes (Lindquist, 1995) (path 1-2). The instrumental theory of procedural fairness (Thibaut and Walker, 1975; Lind and Tyler, 1988) proposes that fairness of procedures may lead to fairer decisions (outcomes). Greenberg and Folger (1983: 236) explain as follows: 'If the process is perceived as being fair, then there is a greater likelihood that the outcomes resulting from that process will be considered fair. The tendency for ... procedural justice to influence ... distributive justice ... has been called the fair process effect.'

The self-interest model proposes similar effects (Lind and Tyler, 1988). This model theorises that the effects of procedural fairness on satisfaction are likely to be through its ability to generate fair outcomes. It proposes that because of self-interest, people are interested in getting the best outcomes.
They also perceive that in the long run, they may be better off with social intercourse. However, with such social intercourse, they may have to sacrifice their short-term gains in order to accommodate the self-interests of other members. How can they be assured that they will get their long-term gains? The model proposes that they will react more positively to fair procedures on the expectation that such fair procedures are more likely to deliver the long-term gains they desire. The consequence of receiving fair outcome is likely to be higher satisfaction. Greenberg and Folger (1983: 239) succinctly suggested that fair procedures are likely to let "people get what they want. Certainly it should be no great surprise that people who get what they want are happier.'

Based on the above discussion, it is reasonable to conclude that fairness of the evaluation procedures is likely to lead to fairer performance evaluations and more equitable compensation for the subordinates (path 1-2). Subordinates who receive fair evaluations and fair compensation are likely to be more satisfied (path 2-5). Accordingly, we propose that:

H1a Fairness of performance evaluation procedures is positively related to fairness of outcomes (distributive fairness) (path 1-2).

H1b Fairness of outcomes is positively related to job satisfaction (path 2-5).

If H1a and H1b are both supported, they would support the expectation that the effect of procedural fairness on job satisfaction is indirect through fairness of outcomes. Hence, we also propose that:

H1c Fairness of performance evaluation procedures has an indirect effect on job satisfaction through fairness of outcomes (path $1-2-5)$.

\subsection{Intervening effects of trust and organisational commitment}

The relationship between fairness of performance evaluation procedures and job satisfaction may involve other considerations that lie below the superficial simplicity of hypotheses $\mathrm{H} 1 \mathrm{a}, \mathrm{H} 1 \mathrm{~b}$ and H1c. Lind and Tyler (1988) suggest that the effects of procedural fairness may be non-instrumental. These effects are those which are over and above the outcome-based effects. They occur regardless of whether the subordinates ultimately receive fair rewards for their effort.

The group value model of Lind and Tyler (1988) proposes that organisational (group) procedures which treat members fairly engender positive organisational outcomes, not because such procedures lead to fair outcomes but because of the importance people attach to group identification and affiliation. This model suggests that people, 
who by nature are affiliate creatures, value group membership per se. Hence, fairness in the way people are treated by their groups is important because it is perceived as 'a visible marker of group membership' and provides the recipient the 'dignity as a full-status member of the group' (Lind and Tyler, 1988: 236-237). Fairness of procedures may therefore enhance job satisfaction, not merely because it leads to fairer outcomes but because it may engender positive outcomes associated with group membership, including trust in superior and organisational commitment.

\subsection{Fairness of performance evaluation procedures and trust in superior (path 1-3)}

Fairness of performance evaluation procedures is likely to enhance the subordinates' trust in their superiors (Hopwood, 1972; Otley, 1978; Magner and Welker, 1994; Magner et al., 1995). Rousseau et al. (1998: 395) define trust as 'a psychological state comprising the intention to accept vulnerability based upon positive expectations of the intentions or behavior of another.' Management accounting procedures are designed, implemented and enforced by organisations through their senior management. Hence, subordinates are likely to attribute the fairness of procedures to their superiors. If the procedures used are perceived as fair, the subordinates are likely to have favourable impressions of their superiors. Accordingly, they are likely to perceive their superiors as trustworthy.

Additionally, performance evaluation procedures may be perceived as fair if they conform to fairness rules. Based on theoretical reasoning, Leventhal (1980) develops several fairness rules. Those that are supported by empirical investigations include consistency, accuracy of information, representativeness and ethicality (Barrett-Howard and Lamm, 1986; Barrett-Howard and Tyler, 1986). Consistency refers to the consistent application of procedures. Procedures are also perceived as fair if decisions are based on accurate information. Representativeness suggests that the concerns, values and outlook of the subordinates are taken into consideration by the superiors. Finally, ethicality reflects that decisions conform to standards of ethics and morality. Procedures which conform to these fairness criteria are likely to engender favourable employee reactions. Consequently, superiors who implement fair procedures are likely to elicit trust from their subordinates. Accordingly, we propose that:

H2a Fairness of performance evaluation procedures is positively related to the subordinates' trust in their superiors (path 1-3).

\subsection{Trust and job satisfaction (path 3-5)}

Trust in superiors is likely to be associated with job satisfaction. It is likely to affect the confidence the subordinates have in their superiors' motives and intentions with respect to matters relevant to their careers and status in the organisation (Read, 1962). If they believe that their superiors are likely to take advantage of opportunities that arise to further their (the subordinates') interests, they are likely to trust their superiors. This may lead to more congenial working relationships which, in turn, may be associated with higher job satisfaction. Moreover, trust is likely to be associated with an environment in which there is much communication between the subordinates and their superiors. In high trust environments, the superiors are likely to be more transparent and more willing to keep their subordinates fully informed about matters of concern to them. The subordinates are also likely to feel free to discuss with their superiors problems and difficulties encountered in task completion, without fear that their careers could be jeopardised. This increased communication may lead to higher job satisfaction.

In contrast, in low trust environments, both the subordinates and their superiors are likely to be less open. Superiors may be secretive and less transparent. Similarly, subordinates may learn that it may be unwise to open up to their superiors. Such a strained working relationship is likely to lead to low job satisfaction. Accordingly, we propose that:

\section{H2b Trust in superiors is positively related to job satisfaction (path 3-5).}

If $\mathrm{H} 2 \mathrm{a}$ and $\mathrm{H} 2 \mathrm{~b}$ are both supported, they would support the expectation that the effect of fairness of evaluation procedures on job satisfaction is indirect through the trust. Accordingly, we propose the following:

H2c Fairness of performance evaluation procedures has an indirect effect on the job satisfaction through trust in superiors (path $1-3-5)$.

\subsection{Fairness of procedures and organisational commitment (path 1-4)}

Organisational commitment comprises three components including continuance, normative (moral) and affective commitment. Allen and Meyer (1990: 3) suggest that 'employees with strong affective commitment remain because they want to, those with strong continuance commitment because they need to, and those with strong normative commitment because they feel they ought to do so.' Porter et al. (1974: 604) define affective organisational commitment as "the strength of an individual's identification with and involvement in a particular organisation ... characterised by ... (a) a strong belief in and acceptance of the organisation's goals and values; (b) a willingness to exert considerable effort on behalf of the organ- 
isation; and (c) a definite desire to maintain organisational membership.' Almost all prior management accounting studies involving organisational commitment have adopted this concept of affective organisational commitment (e.g. Magner and Welker, 1994; Magner et al. 1995; Nouri and Parker, 1998). Consequently, it is also used in our study.

Fairness of evaluation procedures is likely to be associated with organisational commitment (Hopwood, 1972; Folger and Konovsky, 1989; McFarlin and Sweeney, 1992; Magner and Welker, 1994; Magner et al., 1995). Employees are likely to react favourably to an organisation which employs fair procedures. Referent cognition theory suggests that subordinates evaluate their experience by reflecting on 'what might have been' under different situations (Folger, 1986; Lindquist, 1995; Magner et al., 1995). If they perceive their compensation as inadequate, but the organisation's procedures for the determination of performance and compensations as fair, they are not likely to blame their organisation for their inadequate compensation, since they will find it difficult to envision that more favourable alternative outcomes could have occurred, given that procedures are already fair (McFarlin and Sweeney, 1992). However, if they perceive their compensation as inadequate, and their organisation's procedures for the determination of performance and compensation as unfair, they are likely to reflect on what might have been, had the procedures been fair. Consequently, they may hold unfavourable views of their organisation and hence low organisational commitment. Based on the above discussion, we propose as follows:

H3a Fairness of evaluation procedures is positively related to organisational commitment (path 1-4).

\subsection{Organisational commitment and job satisfaction (path 4-5)}

Several researchers (e.g. Steer, 1977; Bateman and Strasser, 1984; DeCotiis and Summers, 1987) have argued that highly committed employees may experience higher job satisfaction. Porter et al. (1974: 604) and Mowday et al. (1979: 226) both associate affective organisational commitment with three characteristics, namely, 'a strong belief in and acceptance of organisational goals; a willingness to exert considerable effort on behalf of the organisation and a definite desire to maintain organisational membership'. Since these are all work-related, it is likely that high affective commitment is associated with high job satisfaction.

Highly committed employees are likely to view organisational goals as important. Hence, they may exert effort to pursue these organisational goals without the need to be coerced. Under such conditions, job satisfaction is likely to be high because the completion of tasks is associated with the achievement of organisational objectives, which gives satisfaction to highly committed subordinates. In contrast, subordinates with low organisational commitment are primarily concerned with pursuing self-interests. Whilst they may exert effort to complete their tasks, it is likely that they may do so because of pressure, coercion or fear of jeopardising their careers. This is unlikely to enhance their job satisfaction. Accordingly, we propose that:

H3b Organisational commitment is positively related to job satisfaction (path 4-5).

If $\mathrm{H} 3 \mathrm{a}$ and $\mathrm{H} 3 \mathrm{~b}$ are both supported, they would support the expectation that the effects of fairness of evaluation procedures on job satisfaction are indirect through organisational commitment. Accordingly, we propose the following:

H3c Fairness of evaluation procedures has an indirect effect on job satisfaction through organisational commitment (path 1-4-5).

\subsection{Trust and organisational commitment (path 3-4)}

Trust in supervisors may be associated with organisational commitment. Organisations are represented by their management and act through them. The subordinates are therefore likely to perceive their organisation through the supervisors who are employed by the organisation to supervise them. Based on their analysis of the organisational commitment literature, Ketchand and Strawser (2001: 231) conclude that organisational commitment 'appears to be particularly influenced by situational factors, such as leader behaviors .... and the extent of leader communications'. Consequently, if the subordinates harbour positive (or negative) feelings toward their superiors, who are, after all, acting on behalf of the organisation, they (the subordinates) are also likely to harbour similar feelings toward their organisation. This suggests that a high level of trust in the superiors is likely to be translated into a favourable attitude towards the organisation. This may lead to the subordinates bonding with the organisation, and hence, high organisational commitment.

Affective commitment reflects an emotional attachment to the employing organisation. It will occur only when the work environment is conducive and harmonious. Allen and Meyer (1990: 8 ) suggest that the extent of the subordinates' feeling of comfort in their relationship with their organisation may influence affective commitment. The extent of the subordinates' comfort in this relationship, in turn, may be affected by variables such as whether the superiors are receptive to subordinates' suggestions, whether the subordinates 
are treated equitably by the superiors and whether there is cohesion between the subordinates and their superiors. These conditions are likely to be determined by the level of interpersonal trust between the subordinates and their superiors. Hence, trust in the superior may be positively associated with organisational commitment. We therefore propose that:

H4 Trust in the superior is positively related to organisational commitment (path 3-4).

\section{Method}

Data were collected by a survey questionnaire. The sample was selected from employees in the health services sector and comprised all the 251 managers from the health services sector of an Australian state. While early studies on procedural fairness were concentrated mostly in legal and political settings, more recent research had found the effects of procedural fairness to be observable in any organisational settings (Leventhal, 1980). As employee performance evaluation is an integral aspect of the management control systems of work organisations, performance evaluation procedures are likely to be one of the most ubiquitous features of organisations. Employees in the health services sector are therefore just as likely to be subject to performance evaluation process as employees in other organisational settings. Hence, a sample drawn from the health services sector is as appropriate as any sample drawn from other sectors where employee performance evaluation occurs.

The names and addresses of managers were drawn from the Health Department Exchange E-mail Global Addresses. ${ }^{1}$ A questionnaire was mailed to each of these 251 managers. Each questionnaire was accompanied by a covering letter, assuring the managers confidentiality of the data collected, and a prepaid reply-addressed envelope for the questionnaire to be returned directly to the researchers. A follow-up letter was sent to each of those managers who had not responded after three weeks of the initial mailing out of the questionnaire.

Six questionnaires were returned unopened and were removed from the sample. Of the remaining sample of 245, a total of 112 were returned. Two of these were not usable, as the focal variables were not fully completed. This left the study with 110 usable responses which constitutes a response rate of $45 \%$. In order to test for non-response bias, the procedures suggested by Oppenheim (1992) were used. These involved splitting the sample into two halves. T-tests were undertaken for the variables studied to ascertain if there were any significant

\footnotetext{
' Permission was granted by the Health Services to use these e-mail addresses.
}

differences between the responses from the first half of the sample (earlier responses) and those from the second half of the sample (later responses). Oppenheim (1992) suggests that if later responses differ significantly from earlier ones, non-response bias may be present. The lack of significant differences found for any of the variables in this study suggests the absence of a response bias.

The mean age of the respondents was 47.9 years. The respondents had held their current positions for an average of 5.8 years and had 12.8 years of experience in their area of responsibility. They were responsible for an average of 59 employees. Seventy-eight percent of them had either a tertiary or a professional qualification. These demographic data indicate that the respondents were generally highly qualified and experienced managers who held very responsible positions.

\section{Measurement instruments}

Fairness of performance evaluation procedures

We use the instrument devised by McFarlin and Sweeney (1992) to measure procedural fairness because it is designed expressly to measure employees' perceptions of the level of fairness of the procedures employed for determining their performance and compensation (Lau and Moser, 2008). It comprises four items which ask the respondents to rate the fairness of the procedures used in their organisations to evaluate employee performance, determine promotions, communicate performance feedback and determine pay increases. An overall fairness of procedures score for each respondent is ascertained by summing the scores of the four items. The factor loading results of a confirmatory factor analysis indicate that all items loaded above the 0.5 benchmark. A Cronbach alpha of 0.78 is obtained. This indicates satisfactory internal consistency for the items in the instrument.

\section{Fairness of outcomes (distributive fairness)}

Two existing instruments are available to measure fairness of outcome. The first was developed by Hopwood (1972) and was also used by Otley (1978). It comprises a single item which asks the respondent to rate 'How justly do you think your performance is evaluated?' The second is a fiveitem instrument developed by Price and Mueller (1981). This instrument asks respondents to rate the fairness of the rewards that they received taking into consideration the amount of effort that they had put forth, the responsibilities that they had, the stresses and strains of their jobs, the amount of education and training that they had and the work that they had done well. We use the instrument developed by Price and Mueller (1981) because its five items permit reliability tests to be 
undertaken. The Cronbach alpha of 0.95 indicates high internal consistency. Satisfactory factor loading results of above 0.5 from a confirmatory factor analysis are found for the four items.

\section{Trust in the superior}

We use Read's (1962) four-item instrument to measure trust in the superior. The items ask each respondent to rate: (i) the extent to which the respondent's superior takes advantage of opportunities to further the respondent's interests; (ii) the extent to which the respondent feels free to discuss with the superior the problems and difficulties in the respondent's job without jeopardising the respondent's position; (iii) the confidence the respondent feels that the superior keeps the respondent fully and frankly informed; and (iv) the trust the respondent has that the superior's decisions are justified when the superior's decisions seem to be against the interests of the respondent. According to Read (1962: 8), these items are intended 'to reflect the manager's trust and confidence in the superior's motives and intentions with respect to matters relevant to the subordinate's career and status in the organisation.' Several prior management accounting studies have also used this instrument (e.g. Hopwood, 1972; Otley, 1978; Ross, 1994; Magner and Welker, 1994; Magner et al., 1995). The Cronbach alpha of 0.83 indicates high internal consistency for the instrument. Satisfactory factor analysis results with loading in excess of 0.5 are found for all items.

\section{Organisational commitment.}

The nine-item, seven-point Likert-scaled shortform version of the Organisational Commitment Questionnaire (OCQ) developed by Porter et al. (1974) is chosen to measure organisational commitment. Almost all prior management accounting studies involving organisational commitment have used this instrument (e.g. Magner and Welker, 1994; Magner et al. 1995; Nouri and Parker. 1998). Cohen (1993) finds an overwhelming majority of 29 out of the 36 investigations in 34 studies he reviewed relied on this instrument to measure organisational commitment. It has also been tested rigorously and successfully by Mowday et al. (1979) for its psychometric properties.

In our study, the Cronbach alpha for the seven items is 0.89 which provides support for high internal consistency. The factor loading results indicate that eight of the nine items have factor loadings equal to or in excess of 0.5. Only one item has a factor loading of 0.39 which is not too far below the 0.5 benchmark. Prior studies which relied on this instrument have generally used all the nine items to measure organisational commitment. Moreover, as the fit indices from the struc- tural modeling analysis indicate acceptable model fit (to be discussed further in the Results section), we use all nine items to measure organisational commitment.

\section{Job satisfaction}

Job satisfaction is measured by the 20 -item short form version of the Minnesota Satisfaction Questionnaire (MSQ). This instrument was developed by Weiss et al. (1967). A five-point scale anchored at ' 1 ' for 'Not satisfied' to ' 5 ' for 'Extremely satisfied' is used. The short-form version of the instrument, instead of the 100-item long-form version, is adopted to keep the questionnaire to a manageable length, since senior managers with time constraints may not be willing to respond to lengthy questionnaires.

As the 20 items for the job satisfaction are made up from 20 different job facets (e.g. satisfaction with superior, pay, chance of promotion, working conditions), a confirmatory factor analysis is not undertaken as these items are each already a separate subdimension of overall job satisfaction. As the subscales are the subdimensions of overall job satisfaction, the sum the scores of these subdimensions is an appropriate measure of employee overall job satisfaction. Hence, the overall job satisfaction score is derived by a summation of the 20 subscale scores. This summation approach is prevalent in the literature. Prior management accounting studies which adopt this instrument include Brownell (1982), Chenhall and Brownell (1988), Frucot and Shearon (1991) and Harrison (1992). All have adopted the summation approach to derive a composite score to represent overall job satisfaction. Descriptive statistics of the variables investigated in this study are presented in Table 1.

\section{Results}

Given the relationships of the theoretical model in Figure 1, the structural equation modeling (SEM) technique is used. We select it because, apart from its ability to model relationships among multiple predictors and criterion variables and construct unobservable latent variables, it is also able to evaluate the relative importance of the various direct and indirect links among variables and as such helps in the understanding of the causal mechanism among variables. We use AMOS Version 7 for the analysis.

The structural model is undertaken with all the items in the questionnaire for each construct, as discussed in the Measurement Instruments section, except for the job satisfaction construct. For the job satisfaction construct, a single score comprising the sum of all 20 items for this construct is used for each respondent.

The results of the structural equation model provide a chi-square of 349 with 223 degrees of free- 
Table 1

Descriptive statistics and Cronbach alphas

\begin{tabular}{lccccccc} 
& & & \multicolumn{2}{c}{$\begin{array}{c}\text { Theoretical } \\
\text { range }\end{array}$} & \multicolumn{2}{c}{$\begin{array}{c}\text { Actual } \\
\text { range }\end{array}$} & Cronbach \\
\cline { 5 - 8 } Variables & Mean & Std dev & Min & Max & Min & Max & alpha \\
\hline Fairness of procedures & 13.23 & 2.88 & 4 & 20 & 6 & 20 & 0.78 \\
Trust in superior & 13.70 & 3.56 & 4 & 20 & 5 & 20 & 0.83 \\
Organisational commitment & 42.70 & 9.61 & 9 & 63 & 16 & 63 & 0.89 \\
Fairness of outcomes & 15.17 & 5.07 & 5 & 25 & 5 & 25 & 0.95 \\
Job satisfaction & 69.83 & 11.24 & 20 & 100 & 44 & 98 & N/A
\end{tabular}

Table 2

Fit indices

\begin{tabular}{lcccc} 
Model & TLI & CFI & IFI & RMSEA \\
\hline Default model & 0.910 & 0.921 & 0.922 & 0.072 \\
Independence model & 0.000 & 0.000 & 0.000 & 0.240
\end{tabular}

dom, returning a probability value of less than 0.001 . By convention, the chi-square test suggests that if the probability value (p) is less than 0.05 , the null hypothesis that the model fits the data is rejected (Bacon, 1997). Since our result has a probability smaller than 0.05 , it suggests that our model does not fit the data. However, as the chisquare test is an absolute test of model fit and is sensitive to sample size, the chi-square results may be attributed to our small sample size (Browne and Mels, 1994). Our sample size is only 112 , which is considerably smaller than the recommended 200 to 400 cases needed for fitting model by chi-square statistics (Bacon, 1997). Moreover, the modification index values from the structural model are generally quite small with only one pair of residual covariances in excess of 0.5 at 0.533 . There are also no indications of errors or warnings. These results suggest that it is safe for us to proceed to the relative fit statistics to ascertain the extent by which our theoretical model outperforms other baseline models. Table 2 indicates that the TuckerLewis Index (TLI or NNFI) is 0.91. The Comparative Fit Index (CFI) is 0.921 and the Incremental Fit Index (IFI or Delta2) is 0.922. By convention, for a model to be accepted, these baseline comparison fit indices should be equal or greater than 0.90 (Segars and Grover, 1993; Hartwick and Barki, 1994; Bentler, 1995). Since the indices for the theoretical model in our study are all in excess of 0.90 , they indicate acceptable model fit. Table 2 also indicates that RMSEA is 0.072 . By convention, there is adequate model fit if RMSEA is less than or equal to 0.08 (Arbuckle, 2006). Based on these results, we use the standardised direct effects (path coefficients), the standardised indirect effects and the standardised total effects generated by the structural equation for hypotheses testing.

\subsection{Hla, H1b, H2a, H2b, H3a, H3b and H4}

Table 3 presents the zero order correlations between the variables investigated in this study. These results indicate that the correlation between fairness of procedures and job satisfaction is highly significant $\left(r_{15}=0.377 ; p<0.01\right)$. Further analyses are needed to ascertain the nature of this significant effect.

$\mathrm{H} 1 \mathrm{a}, \mathrm{H} 1 \mathrm{~b}, \mathrm{H} 2 \mathrm{a}, \mathrm{H} 2 \mathrm{~b}, \mathrm{H} 3 \mathrm{a}, \mathrm{H} 3 \mathrm{~b}$ and $\mathrm{H} 4$ each predict a significant relationship between their respective two variables. The results in Table 3 indicate that the zero order correlation coefficients for all these relationships are highly significant. Specifically, the zero order correlations are significant for the relationships between (i) fairness of procedures and fairness of outcomes $\left(\mathrm{r}_{12}=0.418\right)$ for $\mathrm{Hla}$; (ii) fairness of outcomes and job satisfaction $\left(\mathrm{r}_{25}=0.313\right)$ for $\mathrm{Hlb}$; (iii) fairness of procedures and trust in superior $\left(\mathrm{r}_{13}=0.259\right)$ for $\mathrm{H} 2 \mathrm{a}$; (iv) trust in superior and job satisfaction $\left(\mathrm{r}_{35}=0.533\right)$ for $\mathrm{H} 2 \mathrm{~b}$; (v) fairness of procedures and organisational commitment $\left(\mathrm{r}_{14}=0.407\right)$ for $\mathrm{H} 3 \mathrm{a}$; (vi) organisational commitment and job satisfaction $\left(r_{45}=0.543\right)$ for $\mathrm{H} 3 \mathrm{~b}$; and (vii) trust in superior and organisational commitment $\left(\mathrm{r}_{34}=0.236\right)$ for $\mathrm{H} 4$. These hypotheses are therefore supported. 
Table 3

Zero order correlations between variables

Relations

Zero order effect

Fairness of procedures(1)/Fairness of outcomes(2)

Fairness of procedures(1)/Trust(3)

Fairness of procedures(1)/Organisational commitment(4)

Fairness of procedures(1)/Job satisfaction(5)

Fairness of outcomes(2)/Trust(3)

Fairness of outcomes(2)/Organisational commitment(4)

Fairness of outcomes(2)/Job satisfaction(5)

Trust(3)/Organisational commitment(4)

Trust(3)/Job satisfaction(5)

Organisational commitment(4)/Job satisfaction(5)

$* * * \mathrm{p}<0.01$ (two-tailed)

$* * \quad \mathrm{p}<0.05$ (two-tailed)

$* \quad \mathrm{p}<0.10$ (two-tailed)

5.2. $\mathrm{Hlc}, \mathrm{H} 2 \mathrm{c}, \mathrm{H} 3 \mathrm{c}$ (indirect effects via fairness of outcomes, trust and organisational commitment)

$\mathrm{H} 1 \mathrm{c}$ states that there is an indirect relationship between fairness of evaluation procedures and job satisfaction through fairness of outcomes (distributive fairness). $\mathrm{H} 2 \mathrm{c}$ states that the indirect relationship is through trust. $\mathrm{H} 3 \mathrm{c}$ states that the indirect relationship is through organisational commitment.

In order to ascertain whether each of the hypothesised intervening variables (fairness of outcomes, trust in superior and organisational commitment) mediates the relationship between fairness of evaluation procedures and job satisfaction, it is necessary to decompose the standardised total effect of the relationship between fairness of evaluation procedures and job satisfaction into (i) the standardised direct effect, and (ii) the standardised indirect effects. The standardised direct effects or path coefficients from the structural equation analysis by AMOS are presented in Table 4 and Figure 2.

Based on these path coefficient results in Figure 2 , the indirect effects of fairness of procedures (FP)(1) on job satisfaction (JS)(5) through fairness of outcomes (FO)(2), trust (TR)(3) and organisational commitment $(\mathrm{OC})(4)$ are ascertained as in Table $3 \mathrm{a}$ below.
Path (1-2-5) indicates that the indirect effect exclusively via fairness of outcomes is 0.062 . Path (1-3-5) indicates that the indirect effect via trust is 0.165 . Paths (1-4-5) and (1-3-4-5) indicate that the indirect effect through organisational commitment is $0.199(0.182+0.017)$. An indirect effect in excess of an absolute amount of 0.05 may be considered meaningful (Bartol, 1983; Pedhazur, 1982). For this study, the indirect effects via fairness of outcomes $(0.062)$, via trust $(0.165)$ and via organisational commitment $(0.199)$ are each in excess of 0.05 . Moreover the combined indirect effect is 0.426 out of a total effect of 0.434 . These results support the expectation that the effects of fairness of procedures on job satisfaction are almost entirely indirect rather than direct. Accordingly, H1c, $\mathrm{H} 2 \mathrm{c}$ and $\mathrm{H} 3 \mathrm{c}$ are supported.

\section{Discussion and conclusion}

Fairness is important in organisational settings. Hence, studies on the effects of the fairness of management accounting procedures employed for performance evaluation are needed to provide systematic empirical evidence to explain how the subordinates' perceptions of the fairness of such procedures affect their behaviours and attitudes (Hopwood, 1972; Magner et al., 1995; Horngren

\section{Table 3a \\ Indirect effects}

\begin{tabular}{lccc} 
Path $(1-2-5)$ & FP - FO - JS & $0.445 \times 0.139$ & 0.062 \\
Path $(1-3-5)$ & FP - TR- JS & $0.370 \times 0.445$ & 0.165 \\
Path $(1-4-5)$ & FP - OC - JS & $0.431 \times 0.424$ & 0.182 \\
Path $(1-3-4-5)$ & FP - TR - OC- JS & $0.370 \times 0.108 \times 0.424$ & 0.017 \\
\hline Total indirect effect & & & 0.426
\end{tabular}


Table 4

Standardised direct, indirect and total effects

\begin{tabular}{|c|c|c|c|c|}
\hline $\begin{array}{l}\text { Independent } \\
\text { variables }\end{array}$ & $\begin{array}{l}\text { Dependent } \\
\text { variables }\end{array}$ & $\begin{array}{l}\text { Direct } \\
\text { effects }\end{array}$ & $\begin{array}{l}\text { Indirect } \\
\text { effects }\end{array}$ & $\begin{array}{l}\text { Total } \\
\text { effects }\end{array}$ \\
\hline Fairness of procedures & Fairness of outcomes & 0.445 & - & 0.445 \\
\hline Fairness of procedures & Trust & 0.370 & - & 0.370 \\
\hline Fairness of procedures & Commitment & 0.431 & 0.040 & 0.471 \\
\hline Trust & & 0.108 & - & 0.108 \\
\hline Fairness of procedures & Job satisfaction & 0.008 & 0.426 & 0.434 \\
\hline Trust & & 0.445 & 0.046 & 0.491 \\
\hline Commitment & & 0.424 & - & 0.424 \\
\hline Fairness of outcomes & & 0.139 & - & 0.139 \\
\hline
\end{tabular}

\section{Figure 2}

Path coefficients

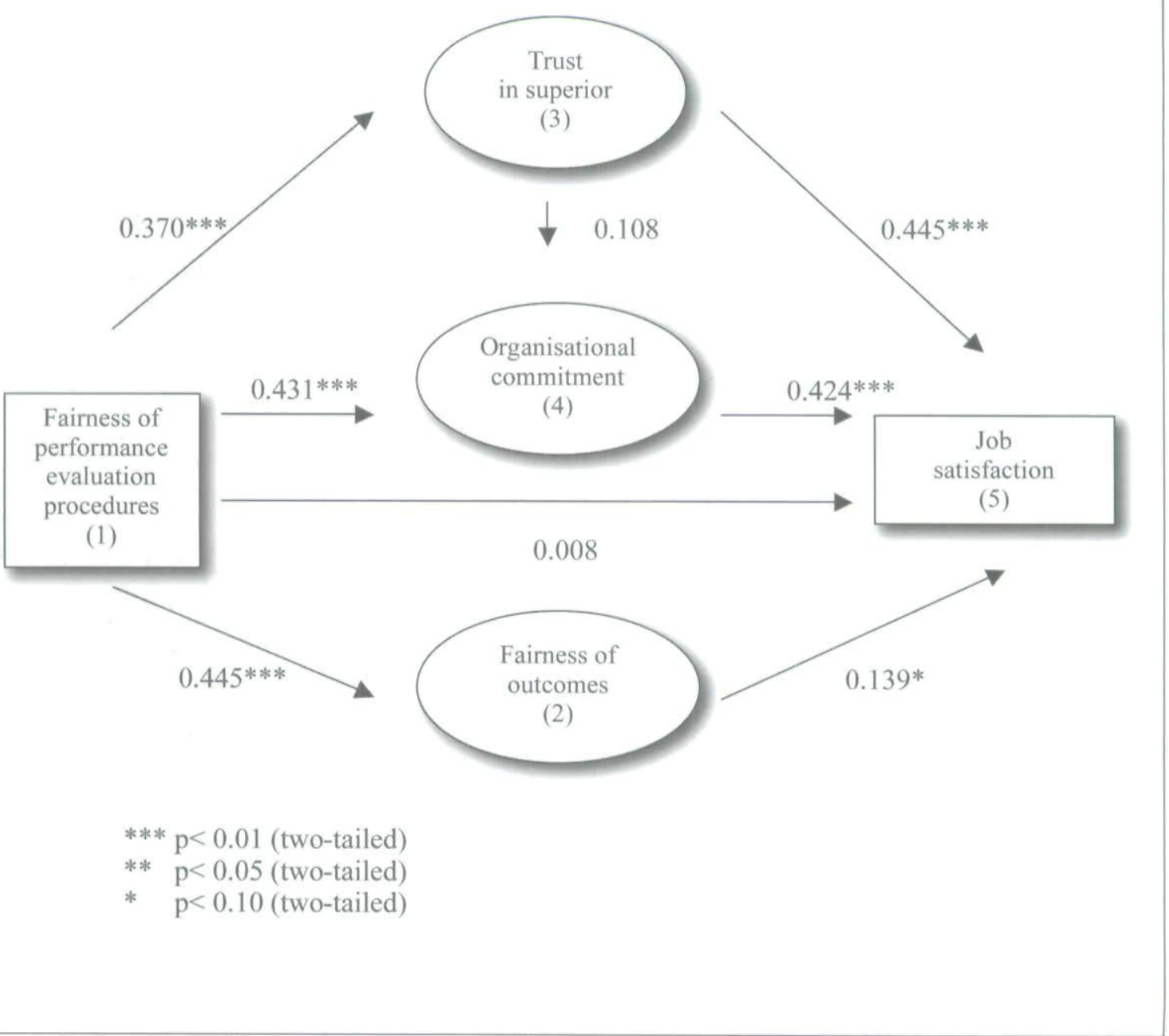


et al., 2006). Our study therefore investigates whether fairness of performance evaluation procedures affects job satisfaction; and if it does, the different cognitive and emotional processes by which it affects job satisfaction.

Our results indicate that fairness of performance evaluation procedures has a significant total effect on subordinates' job satisfaction. However, they also indicate that the direct effect $(0.008)$ is very small. The total effects are mainly indirect. Part of the indirect effect is through the expected fairness of the outcomes (e.g. compensation and rewards) received by the subordinates. These results are not surprising as fair procedures are expected to be associated with fair outcomes which, in turn, are associated with improved job satisfaction. However, what is surprising is the relative small size of this effect, which is only 0.062 out of a total indirect effect of 0.434 . Most of the indirect effect is through trust in superior $(0.165)$ and organisational commitment $(0.199)$.

These results are important for theory development. They provide the empirical evidence to support theories including those by Thibaut and Walker (1978), Leventhal (1980) and the self-interest model of Lind and Tyler (1988). These theories all suggest that procedural fairness effects occur mainly because of the fair outcomes that fair procedures engender. However, because the relative size of the indirect effect through this process is small, our results indicate that this process may be much less important than these theories suggest. As our sample was drawn from managerial level employees from the health services sector, the extent to which the nature of this sample may have influenced the results is unclear. Hence, generalising the results to other levels of employees and to other sectors should be undertaken with caution.

In contrast to the outcome-based effects, our results indicate that the non-outcome-based effects (through trust and organisational commitment) are surprisingly very strong. These results provide strong support for the non-outcome-based models such as the group value model (Lind and Tyler, 1988). This model is based on the premise that "because procedures are very important aspects of the perceptions of groups, evaluation of procedures, in the form of procedural justice judgments, would be expected to have strong effects on other group relevant attitudes ... (and) hardly surprising, then, that procedural justice judgments affect evaluations of leaders and institutions.' Our results are consistent with these observations. They indicate that (1) evaluation of leaders, as measured by the extent of trust in the superior, and (2) evaluation of the institutions, as measured by the level of organisational commitment, are both important effects through which procedural fairness affects satisfaction.
From a theory development perspective, these results may help to explain why apparently different theories of procedural fairness effects, such as the self-interest model and the group value model can each sometime find support in empirical studies, but each is, by itself, unable to explain all procedural fairness effects. Lind and Tyler (1988: 240 ) suggest that their two models encounter difficulty in explaining all procedural fairness effects because "just as the self-interest model has difficulty explaining why such (outcome-based) effects are not as powerful than they are, the group value model, because it makes no reference to outcomes, has difficulty explaining why such effects should occur at all.' (Parenthesis added). Recall that the self-interest model suggests that people perceive procedures solely as instruments for generating equitable outcomes. Lind and Tyler (1988: 226) suggest that for this theory to hold, 'the production of fair outcomes is ... what is meant by fair procedures'. This means that the self-interest theory is able to explain the results of studies where the effects of procedural fairness are attributed to the generation of fair outcomes (e.g. Thibaut and Walker, 1978; Brett, 1986). It is, however, unable to explain the effects of those studies which found effects which are independent of outcomes (e.g. Earley, 1984; Paese, 1985).

Similarly, relying on only the group value model to explain all the effects of procedural fairness is inadequate. This model suggests that people value group membership. Procedures which reinforce their group relationships, for instance, with their superiors and their organisations, are perceived as fair regardless of whether these procedures generate favourable outcomes. Hence, this model is able to explain the results of Earley (1984) and Paese (1985). However, because this model does not consider the importance of outcomes, it is unable to explain why the significant relationships between procedural fairness and fairness of outcomes found in studies such as Thibaut and Walker (1978) and Brett (1986).

Our study suggests that the dilemma posed by the need to use different theories to explain procedural fairness effects is surmountable. These different theories are not invalid. Each is simply incomplete by itself. The use of a comprehensive model which incorporates both (1) the outcomebased effects through distributive fairness, and (2) the non-outcome-based effects through trust and organisational commitment, may minimise confusion. Our results indicate that, studied together within a single model, the two theories provide good explanations of most procedural fairness effects.

Our findings may have important implications for management accounting practices. We select procedures for performance evaluation and com- 
pensation arrangements for investigation because they are major aspects of management control systems. Employees are concerned with performance evaluations because of the close link between performance evaluations and the compensation they receive. Horngren et al. (2006: 845) regard performance evaluation and employees' compensation as intricately linked and conclude that "many management accounting practices ... have as their goal better performance evaluation.' Kaplan and Atkinson (1998: 676) similarly regard performance evaluation and the design of compensation arrangements as crucial management accounting functions because "compensation contracts, particularly incentives and bonus plans, provide important direction and motivation for corporate executives.' Hence, findings on employee reactions to performance evaluation procedures are relevant to management accountants who play crucial roles in the design of these procedures.

While our results are based on a sample from the health services sector, they may be generalisable to other sectors. Procedural fairness reactions occur because of the way people are treated by others. Their reactions generally reflect the way they would like to be treated in social interactions, namely, with respect and dignity (Messick et al., 1985; Mikula, 1986; Greenberg, 1993). Such reactions are more likely to be universal than being unique to specific contexts. Our findings and explanations may have wider implications for management accounting practices than only in the health sector.

Even though support was found for the hypotheses developed for this study, it may have a number of limitations. First, our study is based on survey data. While the survey method is a well-documented research method and has the advantage of capturing naturally occurring phenomena with responses from real managers in a real world setting, it is unable to manipulate variables. Opportunities therefore exist for future research to retest our model with experiments to ascertain whether our results based on the real world setting could be replicated in controlled laboratory conditions.

Second, we have hypothesised that it is organisational commitment which influences job satisfaction. However, the literature suggests that the causal ordering of organisational commitment and job satisfaction is equivocal. While some researchers (e.g. Steer, 1977; Bateman and Strasser, 1984; DeCotiis and Summers, 1987) argue that it is organisational commitment which influences job satisfaction, other studies (e.g. Price and Mueller, 1981; Locke and Latham, 1990) suggest that it is job satisfaction which influences organisational commitment. Other theoretical models may also be possible. For instance, organisational commitment could be the most important situa- tional variable. Similarly, trust may be viewed as a moderating variable. Hence, opportunities exist for future research to collect a bigger sample, include additional constructs and employ different research methods to investigate if these alternative theoretical models could be supported. For instance, the use of a longitudinal analysis may be helpful in resolving the controversy regarding the causal ordering of the various constructs (e.g. organisational commitment vis-à-vis job satisfaction).

Lastly, our study has focused on job satisfaction. While this is an important dependent variable in the study of procedural fairness effects (Lind and Tyler, 1988), employee performance is also important and a practical concern for organisations. Future research could therefore investigate the processes by which procedural fairness affects employee performance. According to Lind and Tyler (1988: 188) 'the relationship between work performance and attitudinal variable is far from straightforward. Performance is multiply determined, and it is probably unreasonable to expect any attitudinal variable, including judgments of procedural fairness, to have simple effects on performance.' Hence, opportunities exist for future research to ascertain whether the model developed for this study could be used to investigate (1) if procedural fairness affects job performance in the same manner as it affects job satisfaction.; or (2) if the effects of procedural fairness on performance is indirect through job satisfaction; or (3) if a different model is needed to study job performance. Some studies (e.g. Libby, 1999; Lau and Moser, 2008) had found procedural fairness to be related to performance. Performance, in turn, may be related to job satisfaction. Employees who perform well may experience high job satisfaction. This suggests that the effects of procedural fairness on job satisfaction may be indirect through job performance. These suggestions provide opportunities for future research to incorporate job performance not only as a possible dependent variable, but also as an intervening variable in the relationships between procedural fairness and attitudinal outcomes.

Notwithstanding the aforementioned limitations, our study provides important empirical evidence and insights into how fairness perceptions of management accounting procedures can affect subordinates' attitudes. Hopefully, this may assist in the development of a unified theory for this research area.

\section{References}

Adams, J.S. (1965). 'Inequity in social exchange', In L. Berkowitz (Ed.) Advances in Experimental Social Psychology, 2: 267-299. New York: Academic Press.

Allen, N.J. and Meyer, J.P. (1990). 'The measurement and antecedents of affective, continuance and normative commitment to the organization'. Journal of Occupational 
Psychology, 63: 1-18.

Arbuckle, J. (2006). AMOS Version 7, Chicago, IL: Smallwaters Corporation.

Bacon, L.D. (1997). 'Using Amos for structural equation modeling in market research'. SPSS White Paper, SPSS Inc.

Barrett-Howard, E. and Lamm, H. (1986). Procedural and Distributive Justice: Definitions and Beliefs of West German University Students. Unpublished manuscript, Northwestern University.

Barrett-Howard, E. and Tyler, T.R. (1986).'Procedural justice as a criterion in allocation decisions'. Journal of Personality and Social Psychology, 50: 296-304.

Bartol, K. M. (1983). 'Turnover among DP personnel: a causal analysis'. Communications of the ACM, 26 : 807-811.

Bateman, T. and Strasser, S. (1984). 'A longitudinal analysis of the antecedents of organizational commitment' Academy of Management Journal, 27: 95-112.

Bentler, P.M. (1995). EQS Structural Equation Program Manual. Encino, CA: Multivariate Software, Inc.

Brett, J. M. (1986). 'Commentary on procedural justice papers'. In Lewiski R., Bazerman, M., and Sheppard, B. (Eds.), Research on negotiation in organizations, 1 . $81-90$.

Browne, M.W. and Mels, G. (1994), RAMONA User's Guide, The Ohio State University, Columbus, Ohio.

Brownell, P. (1982). 'The role of accounting data in performance evaluation, budgetary participation, and organizational effectiveness'. Journal of Accounting Research. 20 (1): 12-27.

Brownell, P. and Dunk, A.S. (1991). 'Task uncertainty and its interaction with budgetary participation and budget emphasis: Some methodological issues and empirical investigation'. Accounting, Organizations and Society, 16(8): 693-703.

Chenhall, R. H. and Brownell, P. (1988). 'The effect of participative budgeting on job satisfaction and performance: role ambiguity as an intervening variable'. Accounting. Organizations and Society, 13 (3): 225-233.

Cohen, A. (1993). 'Organizational commitment and turnover: A meta analysis'. Academy of Management Journal, 36 (5): 1140-1157.

DeCotiis, T.A. and Summers, T.P. (1987). 'A path analysis of a model of the antecedents and consequences of organizational commitment'. Human Relations, 40: 445-470. Earley, P.C. (1984). Informational mechanisms of participation influencing goal acceptance, satisfaction and performance. Doctoral dissertation, University of Illinois, Champaign

Folger, R. (1986). 'Rethinking equity theory: a referent cognition model'. In Justice in Social Relations, edited by Bierhoff, H.W., Cohen, R.L. and Greenberg, J. , 145-164, New York: Plenum Press.

Folger, R. and Konovsky, M.A. (1989). 'Effects of procedural and distributive justice on reactions to pay raise decisions'. Academy of Management Journal, 32 (1): $115-130$.

Frucot, V. and Shearon, W.T. (1991). 'Budgetary participation, locus of control, and Mexican managerial performance and job satisfaction'. Accounting Review, 66: 80-99. Greenberg, J. (1993). 'The social side of fairness: Interpersonal and informational classes of organizational justice'. In Justice in the Workplace: Approaching Fairness in Human Resource Management, edited by Cropanzano, R.: 79-103, Hillsdale, NJ: Lawrence Erlbaum Press.

Greenberg, J. and Folger, R. (1983). 'Procedural justice, participation and the fair process effect in groups and or- ganizations'. In Basic Group Process, edited by P. Paulus: 235-256. New York: Springer-Verlag.

Harrison, G. L. (1992). 'The cross cultural generalizability of the relation between participation, budget emphasis and job related attitudes'. Accounting, Organizations and Society, 17 (1): 1-15.

Hartmann, G.H. (2000). 'The appropriateness of RAPM; toward the further development of theory'. Accounting, Organizations and Society, 25: 451-482.

Hartwick, J. and Barki, H. (1994). Explaining the Role of User Participation in Information System Use. Management Science 40(4): 440-465.

Hopwood, A.G. (1972). 'An empirical study of the role of accounting data in performance evaluation'. Journal of Accounting Research, Supplement, 10: 156-182.

Horngren, C.T., Foster, G. and Datar, S.M. (2006). Cost Accounting, A Managerial Emphasis, 12th edn. PrenticeHall, USA.

Kaplan, R. and Atkinson, A.. 1998. Advanced Management Accounting. 3rd edn, USA: Prentice Hall.

Ketchand, A.A. and Strawser, J.R. (2001). 'Multiple dimensions of organizational commitment: implications for future accounting research'. Behavioral Research in Accounting, 13: 221-251.

Konovsky, M. and Pugh, S. (1994). 'Citizenship behavior and social exchange'. Academy of Management Journal. 37 (3): 656-669

Lau, C.M. and Lim, E. (2002). 'The effects of procedural justice and evaluative styles on the relationship between budgetary participation and performance'. Advances in Accounting, 19: 139-160.

Lau, C.M., Low, L.C. and Eggleton, I.R. (1995). 'The impact of reliance on accounting performance measures on job-related tension and managerial performance: additional evidence'. Accounting, Organizations and Society, 20 (5): 359-381.

Lau, C.M. and Moser, A. (2008). 'Behavioral effects of nonfinancial performance measures: the role of procedural fairness'. Behavioural Research in Accounting, Forthcoming.

Lau, C.M. and Sholihin, M. (2005). 'Financial and nonfinancial performance measures: how do they affect job satisfaction?' The British Accounting Review, 37: 389-423. Leventhal, G.S. (1980). 'What should be done with equity theory? New approaches to the study of fairness in social relationships'. In K. Gergen, M. Greenberg, and R. Willis (Eds.) Social Exchanges: Advances in Theory and Research: 257-55. New York; Plenum Press.

Libby, T. (1999). 'The influence of voice and explanation on performance in a participative budgeting setting'. Accounting, Organizations and Society, 24 (2): 125-137. Lind, E. A. and Tyler, T.A. (1988). The social psychology of procedural justice. New York: Plenum Press.

Lindquist, T.M. (1995). 'Fairness as an antecedent to participative budgeting: examining the effects of distributive justice, procedural justice and referent cognitions on satisfaction and performance'. Journal of Management Accounting Research, 7: 122-147.

Locke E.A. and Latham, G.P. (1990). A Theory of Goal Setting and Task Performance, Prentice Hall, Englewood Cliff, New Jersey.

Locke, E.A. (1976). 'The nature and causes of job satisfaction'. In M.D. Dunnette (Ed.), Handbook of Industrial and Organizational Psychology, 1297-1350, New York: Wiley.

Magner, N. and Johnson, G. (1995). 'Municipal officials' reactions to justice in budgetary resource allocation'. Public Administration Quarterly, 18: 439-457.

Magner, N. and Welker, R.B. (1994). 'Responsibility cen- 
ter manager's reactions to justice in budgetary resource allocation'. Advances in Management Accounting, 3: 237-253.

Magner N., Welker, R.B. and Campbell, T.L. (1995). 'The interactive effect of budgetary participation and budget favorability on attitudes toward budgetary decision makers: A research note'. Accounting, Organizations and Society, 20 (7/8): 611-618.

McFarlin, D.B. and Sweeney, P.D. (1992). 'Distributive and procedural justice as predictors of satisfaction with personal and organizational outcomes'. Academy of Management Journal, 35 (3): 626-637.

Merchant, K. and van der Stede, M. (2007). 'Management Control Systems: Performance Measurement, Evaluation and Incentive', 2nd edn, Prentice-Hall, Upper Saddle River, N.J.

Merton, R.K. and Rossi, A.S. (1957). 'Contribution to the theory on reference group behavior'. In Merton, R.K. (Ed.), Social Theory and Social Structure: 225-280, New York: Free Press.

Messick, D.M., Bloom, S., Boldizar, J.P. and Samuelson, C.D. (1985). 'Why we are fairer than others'. Journal of Experimental Social Psychology, 21: 480-500.

Mikula, G. (1986). 'The experience of injustice: Toward a better understanding of its phenomenology'. In Bierhoff, H.W., Cohen, R.L., and Greenberg, J. (Eds.), Justice in Social Relations: 103-124, New York: Plenum Press.

Mowday, R.T., Steers, R.M. and Porter, L.W. (1979). 'The measurement of organizational commitment'. Journal of Vocational Behavior, 14 (2): 224-247.

Nouri, H. and Parker, R.J. (1998). 'The relationship between budget participation and job performance: the roles of budget adequacy and organizational commitment'. Accounting, Organizations and Society, 23 (5/6): 467-483. Oppenheim, A. N. (1992), Questionnaire Design, Interviewing and Attitude Measurement. London: Pinter Publishers.

Otley, D. T. (1978). 'Budget use and managerial performance'. Journal of Accounting Research 16 (1): 122-149.

Paese, P. (1985). Procedural Fairness and Work Group Responses to Performance Evaluation Procedures. Unpublished thesis, University of Illinois, Champaign.

Pedhazur, E.J. (1982). Multiple Regression in Behavioral Research. New York: Holt, Rinhart \& Winston.
Porter, L.W., Steers, R.M., Mowday, R.T. and Boulian, P.V. (1974). 'Organizational commitment, job satisfaction, and turnover among psychiatric technicians'. Journal of Applied Psychology, 59: 603 - 609.

Price, J.L. and Mueller, C.W. (1981). 'A causal model of turnover for nurses'. Academy of Management, 24: 543-565.

Read, W. H. (1962). 'Upward communication industrial hierarchies'. Human Relations, 15: 3-16.

Ross, A. (1994). 'Trust as a moderator of the effect of performance evaluation style on job related tension: a research note'. Accounting, Organizations and Society, 19 (7): 629-635.

Rousseau, D.M., Sitkin, S.B. Burt, R.S. and Camerer, C. (1998). 'Not so different after all: a cross discipline view of trust'. Academy of Management Review, 23 (3): 393-404.

Segars, A.H., and Grover, V. (1993). Re-examining Perceived Ease of Use and Usefulness: A Confirmatory Factor Analysis. MIS Quarterly 17 (4): 517-525.

Staley, A.B. and Magner, N.R. (2006). 'Budgetary fairness, supervisory trust, and the propensity to create budgetary slack: Testing a social exchange model in a government budgeting context'. Unpublished working paper.

Steer, R.M. (1977). 'Antecedents and outcomes of organizational commitment'. Administrative Science Quarterly, 22: 46-56.

Tang, T.L. and Sarsfield-Baldwin L.J. (1996). 'Distributive and procedural justice as related to satisfaction and commitment'. SAM Advanced Management Journal, 61 (3): 25-31.

Thibaut, J. and Walker, L. (1975). Procedural justice: a psychological analysis. Hillside N.J.: Lawrence Erlbaum Associates

Thibaut, J. and Walker, L. (1978). A theory of procedure. California Law Review, 66: 541-566.

Weiss, D.J., Dawis, R.V., England, G.W., and Lofquist, L.H. (1967). Manual for the Minnesota satisfaction questionnaire. Minnesota studies in vocational rehabilitation, 22. Minneapolis: University of Minnesota, Industrial Relations Center, Work Adjustment Project.

Wentzel, K. (2002). 'The influence of fairness perceptions and goal commitment on managers' performance in a budget setting'. Behavioral Research in Accounting, 14: 247-271. 